\title{
A construção do self marcário em sites de redes sociais à luz do modelo de habilidade social de Michael Argyle
}

\section{The construction of self trademarks on social networking sites in the light of Michael Argyle's social model of skill}

\begin{abstract}
Fernanda Carrera
Doutoranda em Comunicação pela Universidade Federal Fluminense (UFF) e Mestre em Comunicação e Cultura Contemporâneas pela Universidade Federal da Bahia (UFBA). Membro do

Grupo de Pesquisa em Retórica do Consumo (REC/UFF)
\end{abstract}

fernandacarrera@gmail.com

\begin{abstract}
Resumo: Este artigo busca partir das noçóes concebidas no seio da Psicologia Social de Michael Argyle para a compreensão do novo fazer publicitário inserido nos trâmites da cibercultura. Ancoradas pelas práticas interacionais dos indivíduos em sites de redes sociais, as estratégias publicitárias na contemporaneidade parecem instaurar uma outra proposta discursiva: a da interação social propriamente dita com seus supostos consumidores. Neste sentido, pode-se pensar a construçáo do eu da marca sob a luz da produçáo de si dos indivíduos. Tendo como ponto de partida, portanto, o aparato teórico-metodológico da habilidade social de Argyle, busca-se aqui entender os limites e as similaridades encontradas em interaçóes marca-indivíduo com aqueles caracteres previamente compreendidos como específicos da conjuntura relacional dos indivíduos.
\end{abstract}

Palavras-chave: Self; marca; sites de redes sociais; habilidade social

\begin{abstract}
This article seeks conceived notions from within the Social Psychology of Michael Argyle to the understanding of the new procedures do advertising inserted in cyberculture. Anchored by the interactional practices of individuals in social networking sites, contemporary advertising strategies seem to bring another proposal discourse: the social interaction of itself with its supposed consumers. In this sense, one can think of building the brand selfin the light of the individual's production of self. Taking as a starting point, therefore, the theoretical and methodological apparatus of social skill by Argyle, we seek to understand the limits and the similarities found in brand-individual interactions with those characters previously understood as specific relational situation of individuals.
\end{abstract}

Keywords: Self; brand; social networking sites; social skills 


\section{Introdução}

Os novos dispositivos de sociabilidade, mais precisamente representados aqui pelos sites de redes sociais (RECUERO, 2009), foram e são materialidades (FELINTO, 2005) representativas da cibercultura que contribuíram significativamente para a emergência de novas práticas culturais e comunicacionais. Acredita-se, portanto, que a publicidade (uma destas práticas), a partir dos sites de redes sociais, inaugura outra proposta discursiva: a da interação social propriamente dita com os seus supostos consumidores. Sendo assim, a marca transcende a sua característica anterior de subsídio para a construção das relaçôes sociais - sobre a qual sáo projetados valores simbólicos e culturais - para ser, na contemporaneidade, o próprio ator com o qual se interage.

A partir dessa perspectiva, entende-se, portanto, que a mesma lógica de construção do EU do indivíduo, com vistas e ancorado nos ditames das relaçóes sociais, se estende para a construção deste suposto EU da marca. Busca-se neste trabalho, portanto, a compreensão dos processos de construção do seu self, percebendo até que ponto as bases do comportamento social dos indivíduos podem ser identificadas na simulação do Eu marcário para a construção de laços sociais em ambiente digital. Sendo assim, neste artigo, aplica-se o modelo de Habilidade Social de Michael Argyle (1976), percebendo as peculiaridades dessa produção de si; as implicaçóes deste simulacro para as dinâmicas relacionais que são engendradas nestes ambientes; bem como os efeitos para os estudos das estratégias publicitárias no seio cultural contemporâneo.

Vale dizer que, com o intuito de atingir os resultados propostos neste artigo, optou-se por priorizar um recorte mais relacionado ao ambiente do que às marcas analisadas, uma vez que, assim, há uma avaliação mais ampla do uso destes sites para o objetivo estratégico da comunicação publicitária. Além disso, percebe-se uma tendência generalizada em direção à "humanização" das marcas, com vistas a um melhor alcance comercial e estratégico, sendo esta prática incentivada por aqueles que formam o mercado de marketing e publicidade vigente ${ }^{1}$. Portanto, foram escolhidos aqui, como corpus de pesquisa, os sites de rede social Facebook, Formspring e Twitter, em virtude das peculiaridades materiais dos mesmos. Nestes, o foco das práticas engendradas é essencialmente a interação propriamente dita, e não a produção de conteúdo, como nos blogs, por exemplo (RECUERO, 2009). Além disso, os três reúnem em si uma dinâmica temporal acelerada, que exige dos atores sociais uma resposta relativamente rápida aos estímulos advindos dos seus interlocutores. Essa exigência por uma sincronicidade maior reivindica uma habilidade social específica que muito interessa a este trabalho, uma vez que o mesmo intenta descobrir a aplicabilidade do modelo de Argyle (1976) ao contexto digital contemporâneo. 


\section{A construção do self marcário e o novo fazer publicitário}

Tendo como pressuposto o dialogismo constituinte do discurso (Bakhtin, 1986), pode-se dizer que desde a sua concepção a publicidade propôs, de certa forma, uma “interação interlocutiva” (BRANDÃO, 1998, p. 24) com seus públicos. No entanto, identificada pelos estudos como um discurso de sedução (PINTO, 1997), suas configuraçóes de sujeito ancoravam-se na ideia da estereotipia e da identificação (LYSARDODIAS, 2007). Ou seja, parte das estratégias engendradas pelo anúncio publicitário consistia na percepção da identidade do interlocutor - o consumidor participava da produção discursiva a partir da sua concepção pelo enunciador -, para que, assim, o discurso construído refletisse suas aspiraçóes, suas peculiaridades e interesses. Nesse sentido, era predominante a concepção da existência de "uma troca de identidade enquanto 'ser do mundo' e a identidade projectada de um destinatário, 'ser do discurso' (...). O anúncio diz-nos quem somos e como somos, ou seja, fixa os contornos da nossa própria identidade" (PINTO, 1997, p. 31-32).

À marca, portanto, restava existir no discurso enquanto enunciador carente de locutores legitimados para conferir credibilidade ao seu enunciado; à ela não cabia uma personalização independente, única, original. Nesse sentido pode-se dizer que, nessa nova perspectiva comunicacional da marca, regida pelas prescriçóes de sociabilidade, surge uma certa autonomia identitária que oferece à mesma a capacidade de personalizar-se com o objetivo de se tornar interessante à socialização. Isto é, não mais adentra o espelho refletindo o seu consumidor, mas insere-se no mundo como um corpo que pode espelhar-se junto a ele.

$\mathrm{Na}$ figura 1, pode-se reconhecer estes atributos pelas escolhas engendradas pela marca na composição da sua persona interacional: a opção por identificar-se (pela foto escolhida para compor o seu perfil) a partir náo do rótulo do produto, mas apenas de um dos seus elementos que corporificam a silhueta de uma mulher - neste caso, a marca instaura a sua intenção retórica de ser percebida como um simulacro de indivíduo, e não como uma organização; a utilização dos recursos escritos como forma de construção enunciativa de uma persona com características de gênero e humor peculiares àquelas já entendidas no seio cultural como específicas do contexto feminino - a representaçáo de si como algo a ser conquistado e a utilização do diminutivo ("beijinhos”) no trato com o seu interlocutor. 


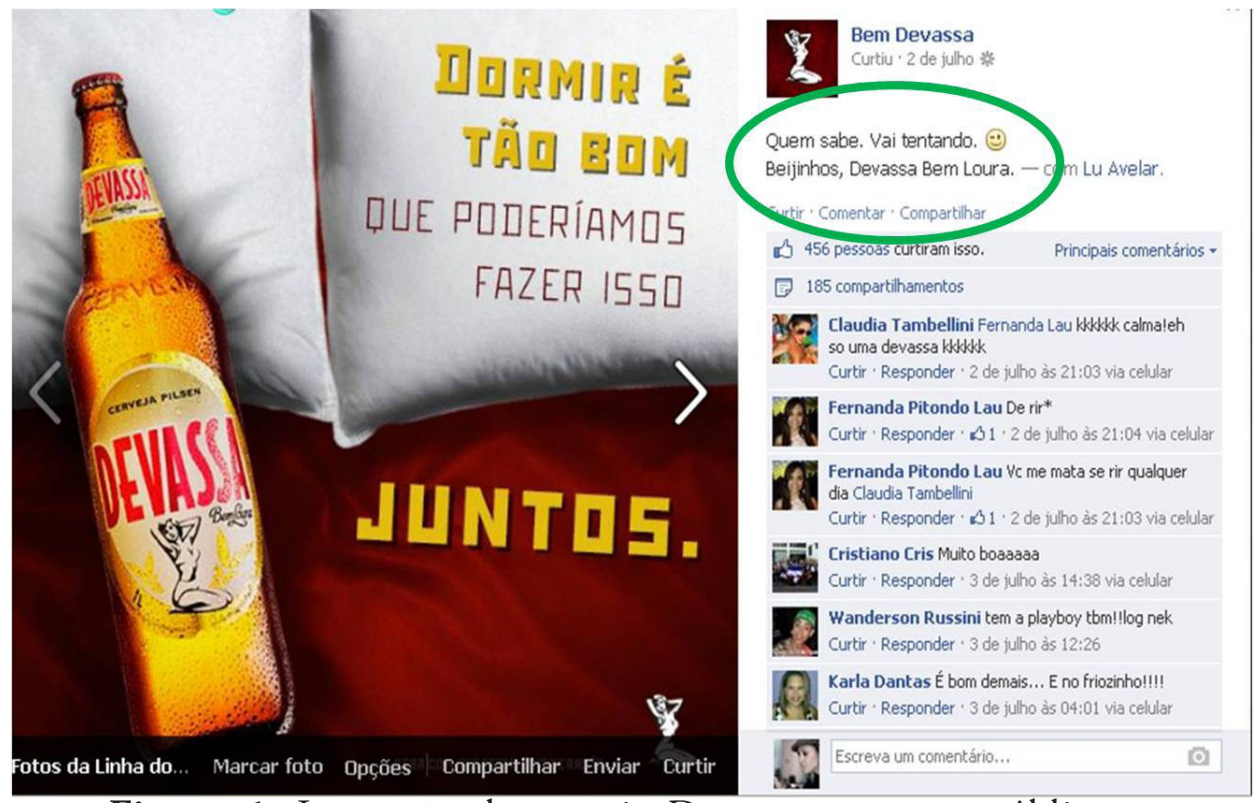

Figura 1: Interação da cerveja Devassa com seu público em sua página do Facebook (em 2 de julho de 2013).

Afirma-se aqui que, enquanto inseridas no invólucro da publicidade, as enunciaçóes propostas pela marca sofrem modificaçóes estruturais importantes principalmente porque constroem outra formação discursiva (FOUCAULT, 2009) a partir de novos caracteres em sua dêixis. Além de inserido em outro tempo e espaço, o discurso da marca estabelece outros sentidos para o que propóe como Eu e Tu nos seus enunciados em meio digital. Na perspectiva aqui proposta, entende-se que aquela fusão entre o Tu (consumidor) e o Eu do produto (PINTO, 1997, p. 162) não se faz mais necessária. Tendo como alicerce os desígnios interacionais, constrói-se a eficácia discursiva pela relevância da relação social que se estabelece, mesmo que fundamentada pelas diferenças. Do ponto de vista do co-enunciador, há um deslocamento entre o "quero ser como" para o "quero interagir com". Nesse sentido, o Tu é essencial na sua alteridade, posto como indispensável à construção daquele que seria o self da marca: aquele que emerge a partir da sua experiência social.

Ao considerar, portanto, as novas formas de socialização, embasadas pelos apelos da cibercultura, pode-se compreender o consumo também a partir deste compartilhamento do fazer, no qual participa-se da produçáo e do consumo quase que simultaneamente. Entende-se que não há mais espaço para o discurso em linearidade, com polos de emissão e recepção bem definidos (LEMOS, 2004, p.15), portanto, o consumir virou interagir; relacionar-se; envolver-se em conversação. A marca se desloca da exclusão do seu ambiente mercadológico para participar das dinâmicas de sociabilidade que ecoam nestes dispositivos tecnológicos atuais. Com o objetivo de serem aceitas pelo grupo social que ali se forma, precisam 
estar atentas às suas normas de comportamento e conduta, tornando-se sujeitos ideais à criação de verdadeiros laços de afetividade; construindo uma imagem de si favorável à socialização.

É nesse sentido que a aproximação da lógica de construção do Eu da marca com a construção do self dos indivíduos se faz pertinente no contexto contemporâneo. Faz parte da construção dos grupos sociais a identificação de atores que se mostram interessantes, legitimados à aceitação. Mais do que isso, constrói-se os referenciais identitários a partir da vida social, realizando contrapontos e semelhanças com aqueles que constituem o Outro (MEAD, 1969, p. 181). Dessa forma, entender a marca como participante dessa conjuntura social é, sobretudo, inseri-la neste seio de construçóes enunciativas, analisando as suas estratégias comunicativas como parte de uma produção contínua de um ator social que se insere no mundo e é submetido por ele.

\section{O self da marca sob os ditames da vida social}

O ponto de partida conceitual necessário a essa análise deve residir na abordagem psicossocial que instaura no sujeito a sua capacidade de construção identitária a partir da vida em sociedade. Isto é, parte-se aqui do pressuposto de que o self é um fenômeno sociológico perceptível: "questôes comumente vistas como qualidades pessoais, propriedades da psicologia do indivíduo, podem ser adequadamente reconceitualizadas como parte de nossa competência social como agentes da interação (SMITH, 2006, p. 97-98). Pensar o self sob essa perspectiva, comum aos estudos do interacionismo simbólico (Mead, 1969; Goffman, 1985; Berger e Luckmann, 1994), é perceber o processo da sua construção como essencialmente dependente das estruturas estabelecidas, anteriores a sua concepção. Logo, o self estaria sempre em construção, respondendo aos estímulos advindos da interação social e da percepção do outro, constituindo-se como um "efeito dramático" (GOFFMAN, 1985, p. 231).

Partindo, portanto, dessa concepção de self, optou-se aqui por entender estas peculiaridades da sua construção, caras ao engendramento da vida social, que são apropriadas para o contexto de uma comunicação estratégica das marcas. Obviamente é possível pensar em diversas nuances simbólicas e interacionais constituintes deste processo de construção de si, contudo buscou-se neste trabalho o foco em uma das características principais dos indivíduos que se aventuram involuntariamente nas sinuosidades da vida em comunidade: a habilidade social. Acredita-se que toda competência comportamental é um produto de uma compreensão construída acerca da sua existência, da existência do outro, e do lugar que se ocupa. Sendo assim, adquirir e construir habilidade social é um pressuposto fundamental para a vida em rede, da qual nenhum indivíduo pode fugir. No caso aqui estudado, no qual se faz uso de um ambiente 
ainda pouco compreendido e em constante modificação - os sites de redes sociais -, esta habilidade (quando existe e quando não) se torna ainda mais evidente. Ou seja, "a internet coloca o mundo social, em todo seu desarranjo e complexidade, na soleira da sua porta” (Fragoso; Recuero; Amaral, 2011, p. 11).

Pretende-se neste artigo, portanto, entender este self construído e simulado pela marca, chamado aqui de self marcário, sob o ponto de vista da Psicologia Social, mais precisamente com base no trabalho de Michael Argyle, intitulado "A Interaçâo Social. Relaçóes Interpessoais e Comportamento Social", de 1976. Neste, o autor - um dos mais influentes teóricos ingleses da Psicologia Social - busca mapear os trâmites das interaçôes sociais, entendendo os encontros como objetos fundamentais para a manifestação do comportamento e da personalidade. Para os interesses aqui explicitados, busca-se maior ênfase no modelo de habilidade social apresentado, alicerce significativo para a compreensão das interaçôes diádicas

\section{A habilidade social da marca: o modelo de Michael Argyle}

De acordo com Argyle (1976), a motivação é um dos principais backgrounds da interação entre dois atores. O objetivo do encontro é construído a priori pelos dois interagentes, podendo consistir tanto na busca por um certo tipo de comportamento do outro, quanto basear-se em algum tipo de padrão interacional. No caso de uma interação diádica marca-indivíduo, a motivação que rege o comportamento da organização é óbvia: construir relacionamento com supostos consumidores com base nas suas estratégias mercadológicas. No caso daqueles que com ela interagem, a motivação parece residir numa certa tendência de cooperação interacional, própria às necessárias representaçóes da vida cotidiana: “a plateia frequentemente cooperará, agindo de maneira respeitosa, com reverente temor pela sagrada integridade atribuída ao ator (GOFFMAN, 1985, p. 68).

Nesse sentido, mesmo propondo o encontro a partir de motivaçóes diferenciadas, é importante, segundo Argyle (1976), que haja um certo equilíbrio comportamental nas escolhas interacionais, fazendo emergir uma relação mais ou menos estável de ações e respostas coordenadas, envoltas em entrosamento. Compreendendo, portanto, os sites de redes sociais como um ambiente essencialmente produzido com fins relacionais (RECUERO, 2009), à marca parece não caber mais um discurso unilateral, guiado pelos princípios normativos da publicidade em meios de massa. Era preciso mergulhar nas especificidades das interaçóes propostas ali, se inserindo nos jogos de manipulação, aprovação, gosto e aceitação social. 
A figura 2 (abaixo) é um exemplo deste mergulho interacional da marca, uma vez que seu ethos (ou sua imagem de si pretendida) é construído a partir da postagem de imagem e texto que se edificam com o que é comumente socializado naquele ambiente, utilizando os recursos e as práticas já estabelecidas como próprias e adequadas àquele espaço relacional. Assim, esta imagem de si edifica-se, também, a partir de um "habitus de classe" (BOURDIEU, 2007, p. 434), isto é, de "subjetividades socializadas" (LANDINI \& PASSIANI, 2007, p. 5) que determinam os gostos e o valor dado a cada comportamento, atitude ou escolha evidenciados pelo conteúdo posto em público. Aqui, a marca Skol utiliza as chamadas "hashtags" 2 para demarcar o conteúdo da sua postagem, enaltecendo um estilo de vida - associado ao uso da bicicleta - muito valorizado na contemporaneidade, como forma de evitar o estresse do trânsito e a poluiçãa do meio ambiente.

De acordo com Bourdieu (2007, p. 434), “o sentido e o valor social da prática ou do bem escolhido (...) assim como o conhecimento prático que os outros agentes têm da correspondência entre bens e grupos”. Assim, utilizar as hashtags e afirmar o uso da bicicleta como melhor forma de locomoção é uma maneira de a marca construir o seu self por meio do habitus da classe de indivíduos que deseja atingir com a sua comunicação estratégica. Este habitus, identificado pela marca, serve à mesma como matéria-prima para a construção da sua subjetividade no ciberespaço, corroborando sua identificação a gostos que atestam a suposta veracidade do ethos que deseja representar.

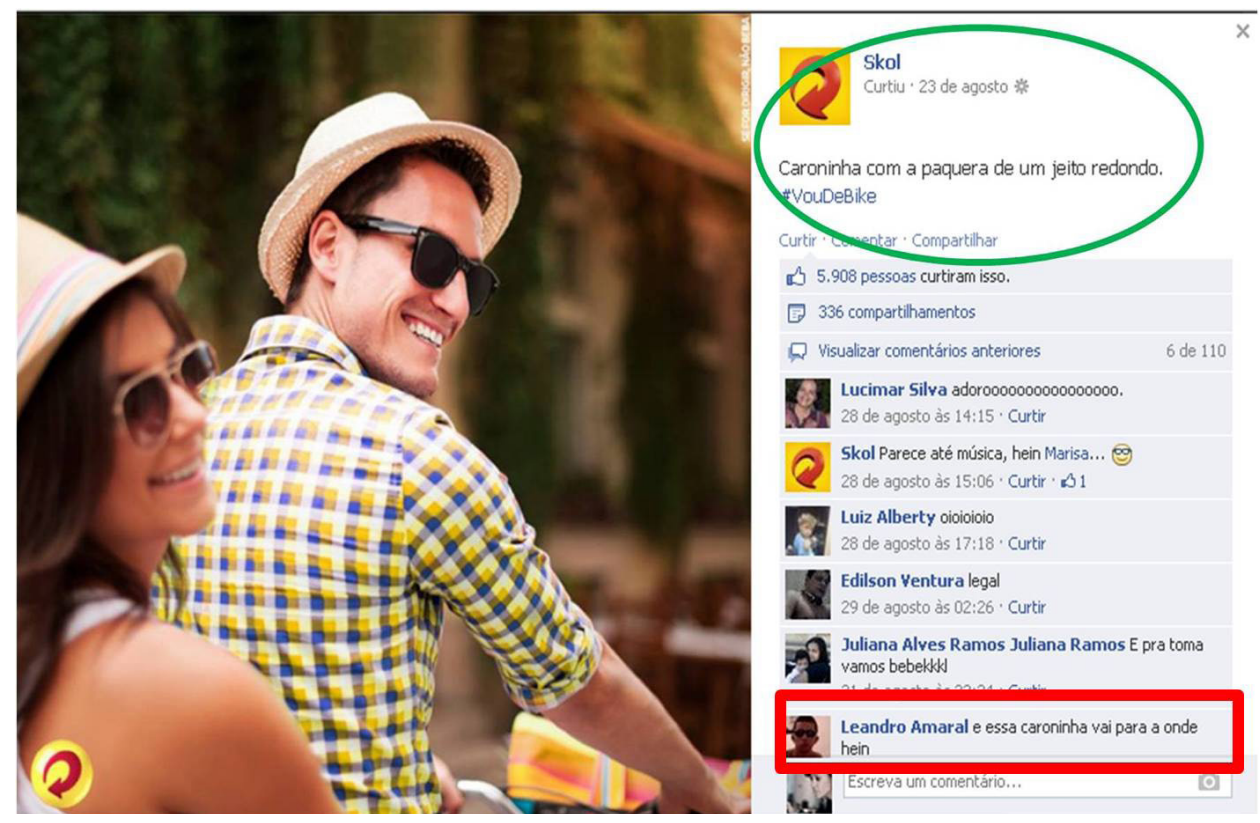

Figura 2: Interação da marca Skol com seu público no Facebook (em 23 de agosto de 2013). 
Nessa perspectiva, assim como os indivíduos, as marcas engendram suas açôes obedecendo a uma estrutura cultural, na qual são introjetados os valores sociais vigentes. Sob a sua ordem, os atores constroem comportamentos dirigidos, e, apesar de muitas vezes estarem automatizados pela tradição cultural, estão longe de ser automáticos, mas gerenciáveis. Assim, as açóes de todos os atores sociais devem estar prescritas por determinadas características próprias à interação: o que Argyle chama de habilidades sociais: "Uma habilidade pode ser definida como uma atividade organizada, coordenada em relação a um objeto ou uma situação, que envolve toda uma cadeia de mecanismos sensoriais, centrais e motores" (ARGYLE, 1976, p. 214).

Segundo o autor, portanto, são cinco os elementos que constituem o modelo da habilidade social, através do qual é possível compreender as dinâmicas interacionais: 1. Os objetivos do desempenho habilitado; 2. A percepção seletiva de pistas; 3. Os processos de tradução centrais; 4. As respostas motoras; e 5. O feedback e a ação corretiva. Intenta-se discuti-los sob o viés da interação marca-indivíduo, percebendo suas semelhanças e especificidades, em uma relaçáo, ademais, inserida nas peculiaridades do ambiente digital.

\section{Os objetivos do desempenho habilitado}

De acordo com o modelo proposto por Argyle (1976), assim como em uma atividade motora, cada indivíduo envolvido em uma interação estabelece as suas açóes a partir de um objetivo. Nesse sentido, sua percepção social é pragmática: é sempre intencional, com finalidades, em busca do fazer pelo falar. Isto é, "cada pessoa quer que a outra responda de maneira associativa, submissa ou dominante, segundo sua própria estrutura motivacional (ARGYLE, 1976, p. 216). Interagir é estabelecer finalidades, seja por meio persuasivo, seja com o objetivo de estabelecer laços que adicionam mais elementos à rede social (ver figura 3). No caso aqui analisado, à marca cabe a criação de textos relevantes, que atraiam a atenção e o possível compartilhamento, construindo elevado capital social (BOURDIEU, 1983) para o estabelecimento de mais e mais fortes interaçôes. 

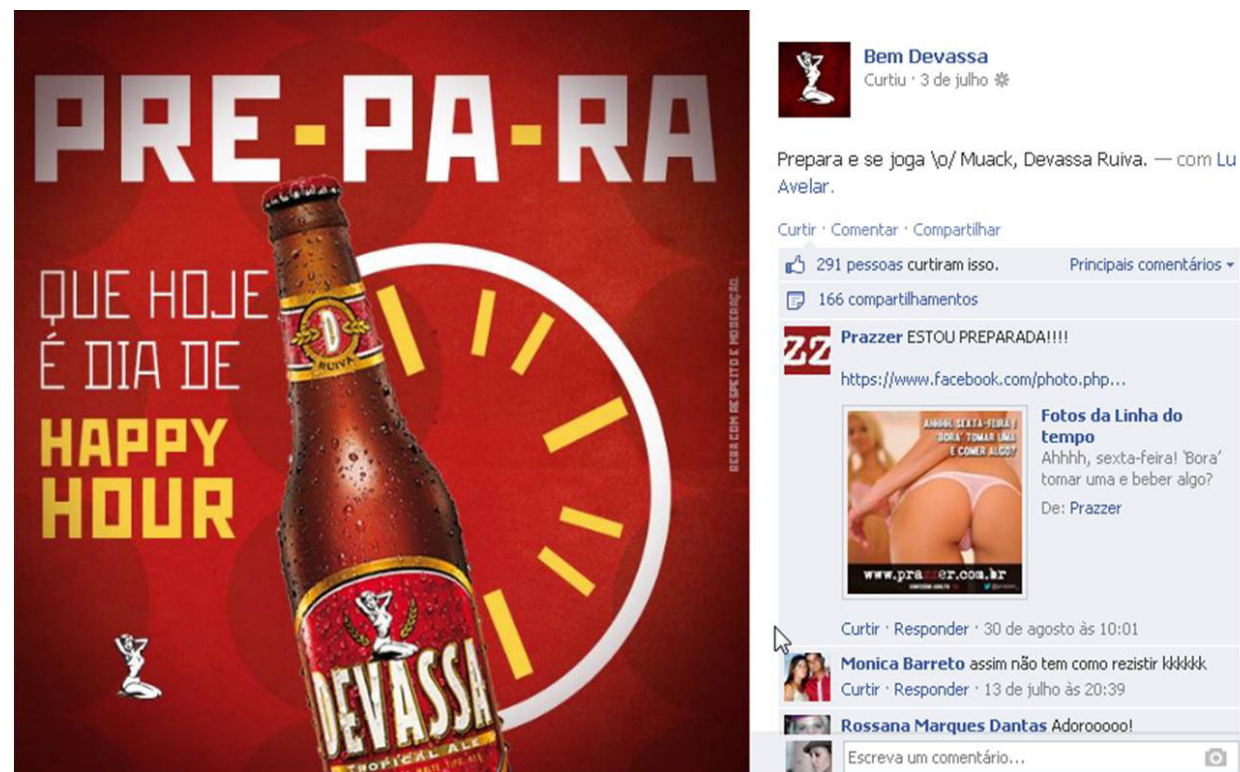

Figura 3: Interação da cerveja devassa na sua página do Facebook (em 3 de julho de 2013).

Compreendendo o ambiente em que se inseriu, portanto, foi possível à marca identificar quais eram aqueles conteúdos mais sujeitos ao compartilhamento (no caso aqui no site de rede social Facebook). Perceber e construir estes memes ${ }^{3}$ é uma forma de espalhar a sua presença digital, atingindo até mesmo indivíduos que não fazem parte da sua rede. Entendendo que as postagens da sexta-feira geralmente são associadas ao fato da chegada do final de semana e do lazer, a marca Devassa aproveitou para oferecer aos seus interagentes um conteúdo pronto sobre o assunto, fazendo uso de uma referência relevante ao momento e aos interesses do seu público. Assim, o objetivo da marca nesta interação é claro: estimular a ação dos indivíduos pelo compartilhamento de um conteúdo interessante, atual e bem-humorado.

\section{A percepção seletiva de pistas}

Com base nas habilidades motoras, Argyle argumenta que um dos principais fatores a serem trabalhados é a sensibilidade a pistas que fornecem informaçóes importantes sobre o caminho a seguir. Nesse sentido, estar atento aos efeitos de sentido do seu comportamento social é uma parte fundamental da habilidade de se construir interaçôes. No caso da interação face a face, objeto de estudo do autor, há formas visuais e audiovisuais de se perceber para onde está caminhando o curso interacional. É a partir delas que se pode mudar a representação; é percebendo as impressôes do outro que é possível gerenciar as imagens produzidas: "as pessoas estão muito interessadas na imagem que estão projetando; um dos objetivos da interação é se apresentar aos outros sob uma determinada luz (ARGYLE, 1976, p. 217).

No campo discursivo, essa luz sob a qual os indivíduos gostariam 
de ser vistos pode ser denominada ethos, imagem de si que prescinde das características empíricas do falante (CHARAUDEAU e MAINGUENEAU, 2004). Regular essa imagem a partir das expectativas da plateia é o que Goffman chama de gerenciamento de impressóes, no qual o efeito percebido é fundamental para a adequação dos efeitos pretendidos pelo ator (ver figura 4). Manipulando de forma coerente a sua fachada, o indivíduo constrói a sua expressividade sob a existência de duas açóes significantes: as expressôes transmitidas e as expressôes emitidas. As primeiras são aquelas de caráter proposital que, por meio de signos conhecidos por sua plateia, fazem eficiente a ação comunicativa. As segundas, por sua vez, incluem movimentos que parecem sintomáticos, não intencionais do ator, e que podem trazer a impressão de que há outros sentidos para aquela informação que fora assim transmitida (GOFFMAN, 1985).

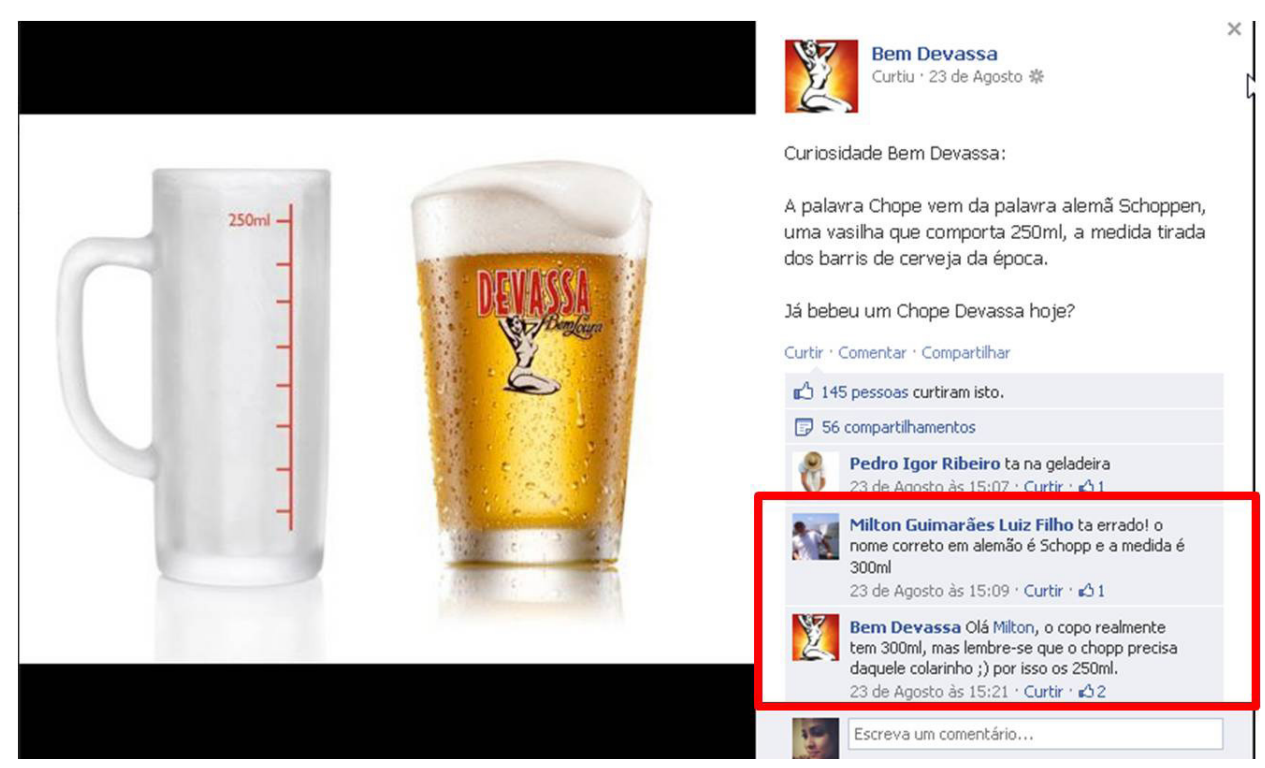

Figura 4: Interação da cerveja devassa na sua página do Facebook (em 23 de agosto de 2013).

A figura 4, dessa forma, exemplifica um típico caso de quebra de expectativas e questionamento de fachada, no qual um indivíduo coloca à prova o conhecimento da marca sobre o próprio produto que coloca à venda. Desta forma, pode-se dizer que a impressão emitida neste caso não correspondeu àquela pretendida intencionalmente pela marca Devassa, representando um risco para a credibilidade da sua imagem de si. Neste processo de construção de sua subjetividade, a marca parece, portanto, perceber as pistas da interação que revelam o momento no qual é necessário corrigir o curso de sua representação, oferecendo uma resposta que volte a manter a sua fachada social. 


\section{Processos de tradução centrais}

O terceiro elemento fundamental conceituado por Argyle consiste no que Mead (1969) chama de “o outro generalizado”. É o conjunto de tradiçóes socioculturais que constitui o todo social e que influencia no campo das experiências de qualquer indivíduo nele inserido. Ou seja, é "a base essencial e o pré-requisito para um mais completo desenvolvimento do self desses indivíduos" (MEAD, 1969, p. 172). Nesse sentido, Argyle afirma que os processos de tradução centrais são apreendidos pela socialização, por meio da qual os indivíduos são dotados de técnicas sociais significativas para a aprovação do grupo desejado. Por exemplo, para conseguir que uma pessoa fale mais, "as melhores técnicas são: 1) falar menos, 2) fazer perguntas abertas, 3) falar sobre coisas nas quais ela está interessada e 4) recompensar qualquer coisa que ela diga" (ARGYLE, 1976, p. 218). No caso da primeira estratégia, é preciso, especificamente no ambiente digital, adequar-se a outro contexto sociotécnico (ver figura 5). Diferente das interações baseadas em co-presença imediata, o ato de falar menos deve ser bem gerenciado, sob o risco de o ator perder presença online: sumir. Pode-se pensar em uma diminuiçáo do discurso monológico, uma vez que ali cabem interaçóes colaborativas, no entanto, estar sempre presente, propondo contatos conversacionais e textos identitários é ditame dos sites de redes sociais. É o imperativo do mostrar-se: "o que se é deve ser visto - e cada um é aquilo que mostra de si” (SIBÍLIA, 2008, p. 235).

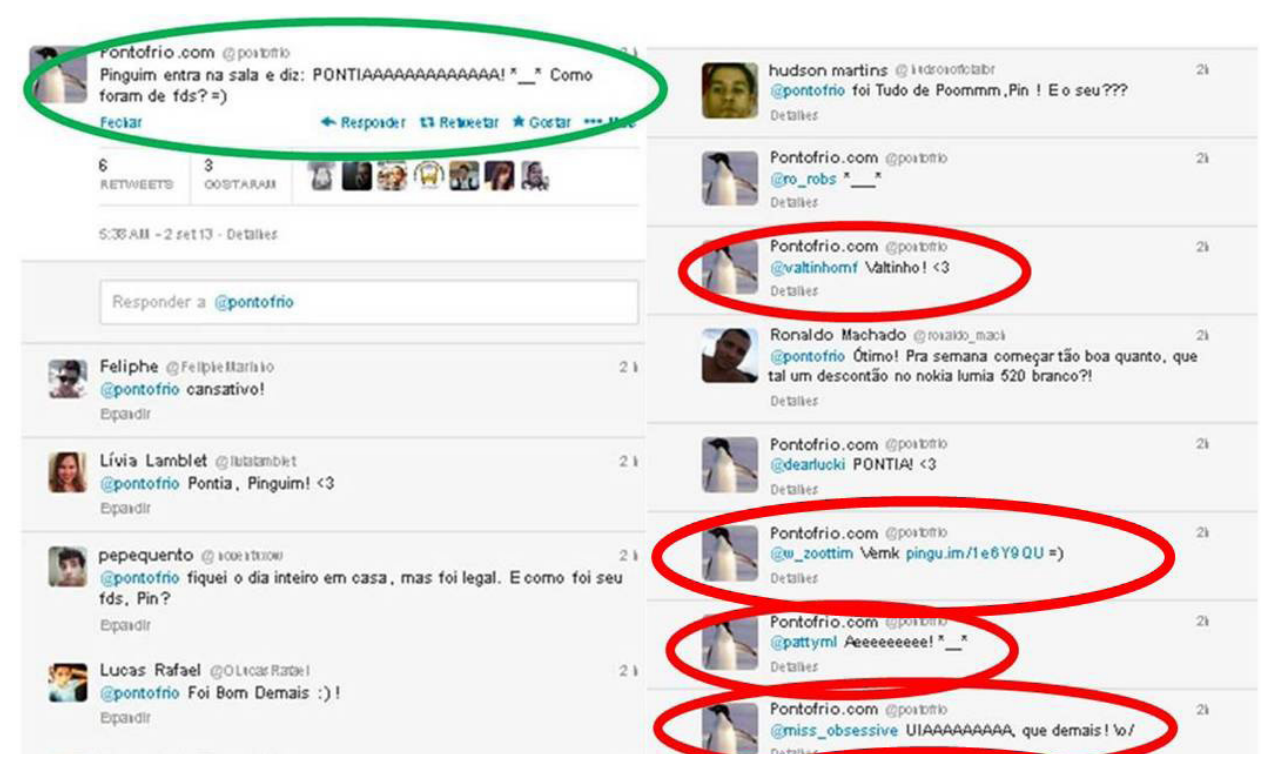

Figura 5: Interação da Ponto Frio no Twitter (em 2 de setembro de 2013).

A figura 5, acima, é um exemplo de como as marcas gerenciam estas estratégias que envolvem o processo de tradução central. Como o ato de falar menos pode configurar-se como prejuízo à presença online, 
as marcas utilizam desta estratégia qualitativamente: falar menos sugere aqui falar menos de si, isto é, de promoçôes, da qualidade do seu produto ou serviço etc. Compreendendo o caráter interacional do ambiente e este novo indivíduo disposto a sempre interagir, a marca reforça a importância da tática de fazer perguntas abertas (aqui a Ponto Frio pergunta sobre o final de semana dos seus seguidores - ver marcação verde); falar sobre assuntos interessantes ao seu interlocutor (no caso aqui, o próprio fim de semana); e recompensar as respostas dadas (mostra aprovação ao que foi comentado, responde a uma possível pergunta e oferece alguma solução a um problema apresentado - ver marcação vermelha).

\section{Respostas motoras}

De acordo com Argyle, "enquanto a essência dos processos centrais é planejar, a essência do sistema de respostas é desencadear e controlar; as respostas desejadas são acionadas e dirigidas com a ajuda de orientação perceptual" (ARGYLE, 1976, p. 219). Deste modo, na habilidade social, assim como em uma habilidade motora, o aperfeiçoamento e o hábito podem levar à redução da atenção do indivíduo sobre os seus movimentos, diminuindo a tensão mas, sobretudo, podendo oferecer o risco de, pela mecanização, haver perda de controle.

Sobre este fenômeno da vida social cotidiana, Goffman alerta para a necessidade de evitar os "atos involuntários" do ator, que estariam, juntamente com as "intromissóes inoportunas" dentro do que o autor chama de "faux pas", ou seja, fatos apresentados por "declaraçóes verbais intencionais ou por atos não-verbais, cujo completo significado não é avaliado pelo indivíduo que contribui com eles para a interação" (GOFFMAN, 1985 , p. 191), o que acaba resultando em constrangimento. No caso da figura 6 (abaixo), é possível perceber o provável "faux pas" empreendido pela marca Fiat no site Formspring $g^{4}$. A marca desconsidera a existência das expectativas da plateia enquanto agentes de construçáo da sua representação e perdeu o controle pela mecanização da resposta, sem controlar o que pode e deve ser dito em adequação ao seu papel social ${ }^{5}$. Por não ter dado a devida atenção à construção da sua fachada, portanto, a Fiat teve de lidar com uma mobilização negativa e contrária à marca, uma vez que permitiu um discurso preconceituoso a uma fachada social que náo condiz com a que pretendia construir naquele ambiente. 


\section{formspring}

Minha namorada quer um rosall Diz não entender o porque de não existir no Brasil a opção rosa para corros com proposta de personalizacĩn rom corec "herrantes".

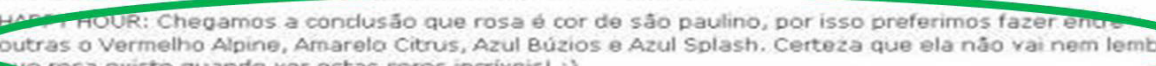
inosa existe quando ver estas cores incriveis! i)

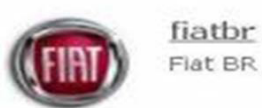

Figura 6: Interação da marca Fiat no site de rede social Formspring (em $1^{\circ}$ de maio de 2010).

\section{Feedback e ação corretiva}

No modelo da habilidade social, o outro é fundamental para as representaçôes empreendidas pelo ator em uma dada conjuntura interacional.

Entender os efeitos de sentido de seu comportamento naqueles com os quais se interage é significativo para o alcance dos objetivos que formam a motivação para o encontro. Argyle afirma, assim como Goffman (1985), que a manipulação dos efeitos no outro faz parte dos alicerces das relaçôes sociais. Isto é, durante o comportamento em sociedade, "geralmente estamos cônscios de sermos o objeto de intençôes, percepções e atitudes por parte dos outros presentes (...).um dos objetivos da interação é a auto-apresentação, isto é, criar certas impressões para os outros (ARGYLE, 1976, p 224). Nesse sentido, identificar e compreender estes feedbacks interacionais é essencial para engendrar ações corretivas, com a finalidade de recuar na construção da fachada e propor um outro curso discursivo para a conversação (ver figura 4). Estar atento às impressóes dos interagentes é entender que as suas percepçôes são determinantes para a adoção de determinados comportamentos, uma vez que estes obedecem a uma estrutura social que se constrói sobre as bases da cultura em vigência.

\section{Cibsuderações finais}

Pensar as novas estratégias de comunicação publicitária sob a égide dos pressupostos psicossociais é admitir a influência significativa dos novos dispositivos sociotécnicos para as práticas culturais contemporâneas. Mais do que invólucros que contêm dinâmicas de sociabilidade, estes sites permitem a reconfiguração dos laços sociais da contemporaneidade, dos artifícios de construção de sentido e, sobretudo, das possibilidades 
enunciativas que envolvem a vida em rede. No entanto, apesar de fazerem emergir estas novas construçóes sociais, pode-se perceber que, muitas vezes, eles apenas tornam mais notáveis práticas tradicionais da vida cotidiana que são fundamentais para a produção interacional dos indivíduos.

A ideia da busca por aprovação social é uma destas características comuns das interaçóes offline que foram expostas mais nitidamente pelo ambiente digital. Por exemplo, a preocupação com a legitimação comportamental do outro e a consequente mudança de comportamento são pressupostos das relaçóes sociais per se, assim como a produção de expectativas a respeito da representação de papeis. Sendo assim, entender os limites das rupturas provocadas pelos dispositivos percebendo a existência significativa das continuidades é essencial para a compreensão destas práticas sociais que emergem no seio contemporâneo. Com esse entendimento, portanto, é possível perceber - o que constitui objeto deste trabalho - as práticas discursivas que assimilam estes trâmites de sociabilidade para a construção do seu texto persuasivo, no caso da publicidade.

Entendendo, portanto, a possibilidade de aplicação de conceitos concebidos para o contexto interacional dos indivíduos para, agora, a conjuntura relacional da marca, pode-se afirmar que os jogos de representação do eu assumem especificidades justamente pela relação com as expectativas oriundas dos seus papeis sociais. E essa concepção de forma alguma anula as semelhanças enunciativas das interaçôes da marca com os indivíduos: nos dois lados, o acordo sobre a definição da situação, dos seus papeis e expectativas, bem como daquilo que se pode ou não fazer e dizer é alicerce de uma boa relação entre os interagentes. No entanto, apesar de ser clara a intenção interacional das marcas nestes ambientes, pode-se questionar o alcance das mesmas a partir da ideia de relação social propriamente dita. Neste caso, segundo Argyle (1976), pressupóe-se uma continuidade de interaçóes e encontros, sob diversos graus de intimidade, e algum tipo de ajuste de personalidades e desejos entre as personagens em questão. Sendo assim, pode-se pensar em específica relação social entre marca e indivíduo? A resposta pode vir de outra questão: é possível pensar em relaçóes sociais unicamente sob os moldes e pressupostos tradicionais dos encontros face a face? 


\section{Referências Bibliográficas}

ARGYLE, M. A interação social: relaçóes interpessoais e comportamento social. [tradução de Márcia Bandeira de Mello Leite Nunes]. Rio de Janeiro: Zahar Editores, 1976.

BAKHTIN, Mikhail (Volochinov). Marxismo e Filosofia da Linguagem. São Paulo: Hucitec, 1986

BERGER, Peter; LUCKMANN, Thomas. A Construção Social da Realidade. Petrópolis: Vozes, 1994.

BRANDÃO, Helena H. Nagamine. Subjetividade, Argumentação, Polifonia. A Propaganda da Petrobrás. São Paulo: Imprensa Oficial e Editora UNESP, 1998

BOURDIEU, P. A distinção: critica social do julgamento. Porto Alegre: Zouk, 2007.

. The forms of Capital. Tradução de Richard Nice.

Goettingen: Otto Shartz \& Co, 1983

CHARAUDEAU, Patrick \& MAINGUENEAU, Dominique. Dicionário de Análise do Discurso. São Paulo: Contexto, 2004

FELINTO, Erick. Materialidades da comunicação: por um novo lugar da matéria na teoria da comunicação. In: CIBERLEGENDA. Rio de Janeiro, RJ, n.5, 2001. Programa de Pós-graduação em Comunicação, Imagem e Informação da Universidade Federal Fluminense. Disponível em: http://www.uff.br/mestcii/felinto1.htm< Acesso em 28 nov.2005

FOUCAULT, Michel. A Arqueologia do Saber. Rio de Janeiro: Forense Universitária, 2009.

FRAGOSO, S.; RECUERO, R.; AMARAL, A. Métodos de pesquisa para internet. Porto Alegre:Sulina, 2011.

GOFFMAN, Erving. A representação do eu na vida cotidiana. Tradução de Maria Célia Santos Raposo. Petrópolis: Vozes, 1985 
LANDINI, T. \& PASSIANI, E. Jogos habituais: sobre a noção de habitus em Pierre Bourdieu e Norbert Elias. In: X Simpósio Internacional Processo Civilizador, Campinas - SP, 2007

LEMOS, André. Cibercultura, cultura e identidade. Em direção a uma "Cultura Copyleft?". Revista Contemporânea,vol.2,no 2 p 9-22, Universidade Federal da Bahia, 2004

LYSARDO-DIAS, D. A Construção e a desconstrução de estereótipos pela publicidade brasileira, Stockholm Rewiew of Latin American Studies, 2007, 2: $25-35$

MEAD, George H. Mind, self and Society. In: COSER, L.A., ROSEMBERG, B. (Eds.) Sociological theory: a book of readings. New York: Macmillam, 1969.

PINTO, Alexandra Guedes. Publicidade: um discurso de sedução. Porto: Porto Editora, 1997

RECUERO, Raquel. Redes Sociais na internet. Porto Alegre: Sulinas, 2009

SIBÍLIA, Paula. O show do eu: a intimidade como espetáculo. Rio de Janeiro: Nova Fronteira, 2008

SMITH, Greg. Erving Goffman. New York: Routledge, 2006

\section{NOTAS}

(1) Sobre isso, ver http://designportugal.net/as-marcas-precisam-ser-mais-humanas-nas-redes-sociais/; http://www.gilgiardelli.com.br/blog/2011/02/21/tendencias-sociais-novos-modelos-de-negocios-e-novas-formas-de-se-comunicar-atraves-das-redes-sociais/; http://www.cafecomblogueiros.com.br/midia-social/humanizacao-das-marcas-e-a-chave-do-sucesso-nas-redes-sociais/; e http://ecommercenews.com. br/artigos/cases/persona-da-marca-parte-importante-da-estrategia-nas-midias-sociais (2) A hashtag é o símbolo \#, seguido de uma palavra ou frase, usado para marcar palavras-chave ou tópicos. Originalmente criado pelos usuários do Twitter, hoje é utilizado também por outros sites de rede social, como o Facebook. Sobre isso, ver 
http://support.twitter.com/articles/49309\#

(3) Conceito utilizado para designar conteúdos construídos com o intuito de viralização digital. Geralmente pautados pelo humor e pela paródia a acontecimentos e personagens vigentes. 4

(4) Site de rede social que permite que usuários recebam perguntas de outros usuários ou até de pessoas não cadastradas. Todas as perguntas aceitas e suas respostas são armazenadas no perfil do usuário, onde qualquer um pode vê-las (ver http://new.spring. me/\#!/welcome?l=\%2Ffeed $\% 2$ Fall)

(5) Neste caso, a montadora propunha uma interação de perguntas e respostas com aqueles que desejavam saber mais sobre o lançamento do Novo Uno. Com três tipos de resposta (No "engenharia", a resposta era técnica; no "marketing”, era comercial, persuasiva; e no "happy hour", era repleta de humor e descontração), a Fiat exagera no humor da terceira resposta e oferece um discurso ofensivo. 